\title{
Electromagnetic Core Analysis of a DFIG State-Feedback Power Controller
}

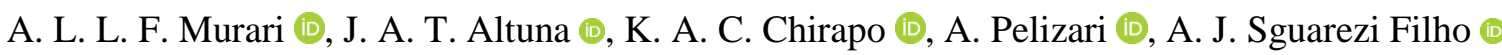 \\ CECS - Federal University of ABC, Santo Andre, SP 09210-580 BRAZIL, andre_murari@hotmail.com, \\ jose.torrico@ufabc.edu.br, ccantuta.karlos@ufabc.edu.br,ademir.pelizari@ufabc.edu.br, \\ alfeu.sguarezi@ufabc.edu.br
}

\begin{abstract}
The energy demand by modern society grows every day that allied with sustainable development requires the use of alternative sources in the new energy matrix. In this context, the wind energy as source by using a doubly-fed induction generator stands out due to its operational savings but still faces some conflicts in its power control. This paper proposes a state feedback plus integral controller for rotor current control. In order to verify the controller operation, an electromagnetic finite element analysis simulation of the interior of the machine was carried out, assuring the non-saturation of the core, which would lead to a control instability and it can increase the machine losses. For this, a machine modeling was presented into state equations in order to establish a power control diagram. The results of electromagnetic simulation and the experimental bench results when united ensure the correct functioning of the proposed system and the satisfactory efficiency of the controller. In this way, it can be concluded that the use of this control technique in counterpart with the conventional PI increases the response time of the system without affecting the electromagnetic dynamics of the generator.
\end{abstract}

Index Terms-Electromagnetic core analysis, DFIG, Power controller.

\section{INTRODUCTION}

The doubly-fed induction generator (DFIG) is a machine consolidated in wind energy systems due to concern about $\mathrm{CO}_{2}$ emissions. The stator of the machine links directly the grid network and its rotor is connected to the power grid by a back to back converter.

In this configuration the rotor of DFIG is connected to the grid through a and the stator is connected directly. The active and reactive power flow between the stator and $\mathrm{AC}$ grid can be made by controlling the rotor applied voltages $[1,2]$. A high performance power control can be reached by stator-voltageoriented [3] or stator-flux- oriented [4] vector control and closed loop using controllers as PI [5].

The classical PI controller had some problems, such its tuning in the whole operating range. The papers $[6,7]$ propose alternative solutions for the cited problem in which the gains are computed for a single operation point. Another solution is to use hysteresis controllers, as proposed in [8]. However, the frequency operation did not fixed and it can increase the losses of the converter. 
In addition, there are power control schemes for DFIG using rotor current loops and predictive functional controller [9] or internal mode controller [10], [11]. Other possibilities to DFIG power control are fuzzy logic [12,13], model based predictive control [14] or sliding mode control [15], [16]. The cite controllers has satisfactory performance when their performance was compared with PI performance.

Regarding the controller's operation, there is no guarantee that the generator operates unsaturated. So, ferromagnetic material can operate oversatured and it can increase the machine losses. In this way, the finite element method (FEM) can aid to analysis the generator operation in the mentioned condition $[17,18]$.

In this context, this paper proposes a state feedback controller using a additional integral mesh current control for a DFIG at variable speed wind profile. The power control algorithm calculates the proportional and integral gains to perform one complex voltage vector that provides the voltage to be applied to the rotor side converter using pole placement. This proposed controller employs (field oriented control) decouples the stator currents, so that, the active and reactive powers should reach their desired reference values by means of properly setting the rotor currents. Also, an electromagnetic finite element analysis simulation of the interior of the machine was carried out to analysis the controller operation assuring the non-saturation of the core. The result obtain in the experimental setup endorse the performance of the controller.

After this brief contextualization contained in the introduction, this paper presents in Section 2 the DFIG machine modeling vector control resulting on the rotor side converter oriented equations, with the proposed augmented state feedback control scheme presented in Section 3. An electromagnetic machine analysis is performed in Section 4 in order to avoid a magnetic system instability. Experimental tests performed in the laboratory on the emulated variable wind generation system are presented in Section 5 to validate the proposed control scheme. Finally, Section 6 concludes the work.

\section{MACHINE MODEL AND ROTOR CURRENT VECTOR CONTROL}

Although power systems are powered by three-phase voltages, it is usual to convert to a synchronous reference system [19]. In the synchronous reference frame the equations the represent the DFIG model is done by

$$
\begin{gathered}
\vec{v}_{s d q}=R_{s} \vec{\imath}_{s d q}+\frac{d \vec{\lambda}_{s d q}}{d t}+j \omega_{s} \vec{\lambda}_{s d q} \\
\vec{v}_{r d q}=R_{r} \vec{\imath}_{r d q}+\frac{d \vec{\lambda}_{r d q}}{d t}+j\left(\omega_{1}-P P \omega_{m e c}\right) \vec{\lambda}_{r d q}
\end{gathered}
$$

on what the relationship between fluxes and currents are:

$$
\vec{\lambda}_{s d q}=L_{s} \vec{\imath}_{s d q}+L_{M} \vec{\imath}_{r d q}
$$




$$
\vec{\lambda}_{r d q}=L_{M} \vec{l}_{s d q}+L_{s} \vec{\imath}_{r d q}
$$

The machine dynamics using the mechanical torque $\mathrm{T}_{\mathrm{M}}$ and the electromagnetic torque is given by:

$$
J \frac{d \omega_{m e c}}{d t}=\frac{3}{2} P P \operatorname{Im}\left(\vec{\imath}_{s d q} \vec{\lambda}_{s d q}^{*}\right)-T_{M}
$$

and the generator, stator provided, active and reactive powers are:

$$
\begin{aligned}
& P=\frac{3}{2}\left(v_{s d} i_{s d}+v_{s q} i_{s q}\right) \\
& Q=\frac{3}{2}\left(v_{s q} i_{s d}-v_{s d} i_{s q}\right)
\end{aligned}
$$

The stator and rotor parameters are represented by the subscripts $s$ and $r$, respectively, $R$ the per phase electrical resistance windings, $\omega_{s}$ the synchronous speed, $\omega_{m e c}$ the rotor speed, $L$ is the properinductances of the windings, $L_{M}$ mutual inductance, $\vec{\lambda}$ the flux vector, $\vec{v}$ the voltage vector, $J$ is the load and rotor inertia moment, $\vec{\imath}$ the current vector, PP the generator pair of poles number, and $\mathrm{T}_{\mathrm{M}}$ the mechanical torque.

Using stator flux oriented control, with $\lambda_{s d}=\lambda_{s}=\left|\vec{\lambda}_{s d q}\right|$ and $v_{s}=v_{s q}=\left|\vec{v}_{s d q}\right|$, decoupling dq axis (3). Hence, independent stator active $\mathrm{P}$ and reactive $\mathrm{Q}$ power control can be reached, representing each one as functions of its respective rotor current component, resulting in:

$$
\begin{gathered}
i_{s d}=\frac{\lambda_{s}}{L_{s}}-\frac{L_{M}}{L_{s}} i_{r d} \\
i_{s q}=-\frac{L_{M}}{L_{s}} i_{r q}
\end{gathered}
$$

So, using (8) and (9) the active (6) and reactive (7) powers can be rewritten as:

$$
\begin{gathered}
P=-\frac{3}{2} v_{s} \frac{L_{M}}{L_{s}} i_{r d} \\
Q=\frac{3}{2} v_{s}\left(\frac{\lambda_{s}}{L_{s}}-\frac{L_{M}}{L_{s}} i_{r d}\right)
\end{gathered}
$$

\section{A. Rotor Side Equations}

At the stator flux oriented the rotor voltage vector by using (2), (8), and (9) turns:

$$
\vec{v}_{r d q}=\left(R_{r}+j \sigma L_{r} \omega_{s l}\right) \vec{l}_{r d q}+\sigma L_{r} \frac{d \vec{l}_{r d q}}{d t}+j \frac{L_{m}}{L_{s}} \omega_{s l} \lambda_{s}
$$

where the angular slip velocity $\omega_{s l}=\omega_{1}-P P \omega_{m e c}$ and the dispersion coefficient $\sigma=1-\frac{L_{M}}{L_{s} L_{r}}$. In the space state form, (12) becomes: 


$$
\begin{gathered}
\dot{\bar{x}}=A \bar{x}+B \bar{u}+G \bar{\omega} \\
{\left[\begin{array}{c}
\frac{d i_{r d}}{d t} \\
\frac{d i_{r q}}{d t}
\end{array}\right]=\left[\begin{array}{cc}
\frac{-R_{r}}{\sigma L_{r}} & \omega_{s l} \\
-\omega_{s l} & \frac{-R_{r}}{\sigma L_{r}}
\end{array}\right]\left[\begin{array}{l}
i_{r d} \\
i_{r q}
\end{array}\right]+\left[\begin{array}{cc}
\frac{1}{\sigma L_{r}} & 0 \\
0 & \frac{1}{\sigma L_{r}}
\end{array}\right]\left[\begin{array}{l}
v_{r d} \\
v_{r q}
\end{array}\right]+\left[\begin{array}{cc}
0 & \frac{\omega_{s l} L_{M}}{\sigma L_{s} L_{r}} \\
-\frac{\omega_{s l} L_{M}}{\sigma L_{s} L_{r}} & 0
\end{array}\right]\left[\begin{array}{c}
\lambda_{s} \\
0
\end{array}\right]}
\end{gathered}
$$

The time constant of mechanical system is greater than the electrical ones, which allows to consider that $\omega_{\text {mec }}=$ constant for each sampling period [20]-[21], ergo, the slip speed $\omega$ sl becomes a constant, since the synchronous speed $\omega_{s}=2 \pi f$ is determined by the infinite grid bar ( $\mathrm{f}=60$ or $50 \mathrm{~Hz}$ ).

\section{STATE FEEDBACK POWER CONTROL}

The state feedback control system allows null error when using an additional external mesh containing an integrator to the tradicional plant. This state feedback controller can be designed by using the overshoot, system frequency, settling time, damping ratio of a second order linear continuous system [22], [23], by means of the equality of its equation coefficients.

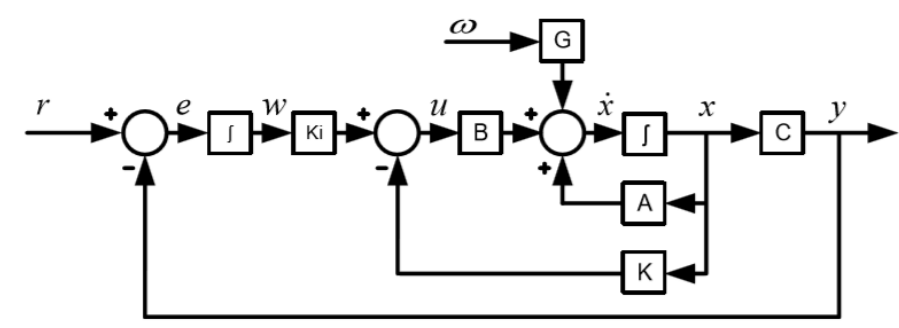

Fig. 1. State feedback plus integral control block diagram.

The usual states system can be described by:

$$
\begin{gathered}
\dot{\bar{x}}=A \bar{x}+B \bar{u}+G \bar{\omega} \\
\bar{y}=C \bar{x}
\end{gathered}
$$

where $C, A, B$ and $G 2 \times 2$ and $\bar{\omega}$ the perturbation vector matrices for this case. In this paper $C$ is the identity matrix. The proposed state feedback plus integrator block diagram is presented in Fig. 1.

The state feedback controller are represented by the gain $\mathrm{K}$ and $\mathrm{Ki}$ and they will be designed using pole placement. The desired poles are obtained by the characteristic second order polynomial system in accordance with classic control using expressions:

$$
\begin{gathered}
\xi=\frac{-\ln (M P)}{\sqrt{\pi^{2}+\ln (M P)^{2}}} \\
\omega_{n}=\frac{4}{\xi t s} \\
\operatorname{pol}_{1,2}=-\omega_{n} \xi \pm j \omega_{n} \sqrt{1-\xi^{2}}
\end{gathered}
$$


$M P$ represents the overshoot in percentage, $\omega_{n}$ is the natural oscillation frequency, $t s$ is the settling time, and $\xi$ is the damping ratio. So, the machine model is separated into two parts and the internal gain of the controller is calculated first. The desired characteristic equation is given by [22]:

$$
H=|s I-A+B k|
$$

As mentioned, the $\mathrm{k}$ gains of the internal closed loop (19) are calculated by using the poles calculated from the characteristic equation (18). The resulting parity is:

$$
|s I-A+B k|=\left(s+p_{1} l_{1}\right)\left(s+p^{2} l_{2}\right)
$$

Although the system is of MIMO type it is possible to reproduce the current mesh doubly into two SISO systems due to the possibility of FOC uncoupling (10)-(11), so that $\mathrm{k}$ is $\mathrm{k}_{1}$ or $\mathrm{k}_{2}$ being the proportional gains of each synchronous current component.

For null steady state error, a new loop to each SISO is added using an Integrator. The equation of the new loop is:

$$
\dot{\bar{q}}=\frac{d}{d t}(\text { error })=\bar{x}_{r e f}-\bar{x}
$$

In this way, the input is given by:

where $k_{i 1}$ and $k_{i 2}$ are the integral gains.

$$
\bar{u}=-k \bar{x}+k_{i} \bar{q}
$$

The new steady state equation using (15) and (21) is given by:

$$
\begin{gathered}
\dot{\bar{x}}_{1}=A_{1} \bar{x}_{1}+G_{1} \bar{\omega}+R \bar{x}_{r e f}+B_{1} \bar{u} \\
{\left[\begin{array}{c}
\dot{\bar{x}} \\
\dot{\bar{q}}
\end{array}\right]=\left[\begin{array}{cc}
A & Z \\
-I & Z
\end{array}\right]\left[\begin{array}{c}
\bar{x} \\
\bar{q}
\end{array}\right]+\left[\begin{array}{c}
G \\
Z
\end{array}\right] \bar{\omega}+\left[\begin{array}{l}
Z \\
I
\end{array}\right] \bar{x}_{r e f}+\left[\begin{array}{l}
B \\
Z
\end{array}\right] \bar{u}}
\end{gathered}
$$

where $\mathrm{z}$ is a zero matrix.

By using (21)-(24) and the diagram shown in Fig. 1, the $k_{i}$ gains are calculated using the modified augmented desired characteristic equation as:

$$
\left|s I-A_{1}+B_{1} k x+G_{1} \bar{\omega}+R\right|=\left(s+\operatorname{pol}_{1}\right)\left(s+\operatorname{pol}_{2}\right)(s+\alpha)(s+\beta)
$$

where the augmented gain matrix $k x=\left[\begin{array}{ll}K & K i\end{array}\right]$.

We don't have the four poles of the characteristic equation, but we know that the first two poles, resulting from the characteristic second order polynomial (related to the $k$ values) are stable, it is possible to displace the other two unknown poles (related to the values of $k_{i}$ ) to the left of the halfplane s, so let be $\alpha=\beta=2 \times\left|p_{1} l_{1}\right|$. Making sure that the real part is negative ensures that the system will be stable. 


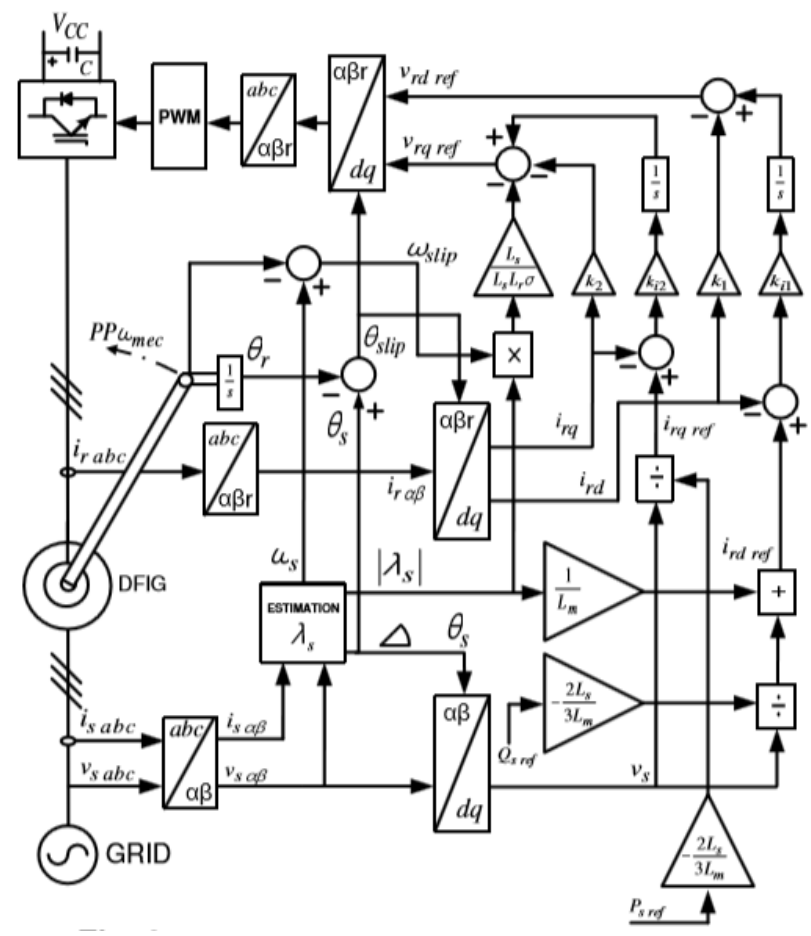

Fig. 2. Complete state feedback power controller.

\section{A. Stator Power Control}

The state feedback controller gains are designed by using the generator model as in (14) and (18)-(25). In this control application, the rotor current is the state variable and the output is the rotor voltage. Only the rotor voltage equation is used due to the fact the volt- ages or current of the stator cannot be manipulate in the presented configuration.

The block diagram of the proposed controller, based on (26) and (27), is shown in Fig. 2.

In order to compensate the e.m.f. $\left(\lambda_{1} \omega_{s l} \frac{L_{m}}{\sigma L_{1} L_{2}}\right)$ a feed forward is added to the quadrature rotor component loop accelerating the control dynamics. Hence, rotor voltage vector of direct and quadrature axis are calculated by:

$$
\begin{gathered}
v_{r d}=\left(i_{r d_{r e f}}-i_{r d}\right) \frac{k_{i s}}{s}-k_{s} i_{r d} \\
v_{r q}=\left(i_{r q_{r e f}}-i_{r q}\right) \frac{k_{i r}}{s}-k_{r} i_{r q}-\lambda_{s} \omega_{s l} \frac{L_{m}}{\sigma L_{s} L_{r}}
\end{gathered}
$$

The gains of (26) and (27) are designed using (18)-(25) and the parameters shown in Appendix.

The rotor current reference of quadrature axis allows the active power control by using (10), is done by:

$$
i_{r q_{r e f}}=-\frac{2 P_{r e f} L_{s}}{3 v_{s} L_{M}}
$$

In the same way, rotor current reference of direct axis allows the reactive power control by using (11). So that, the rotor current reference is:

Brazilian Microwave and Optoelectronics Society-SBMO received 16 Oct 2018; for review 23 Oct 2018; accepted 11 July 2019 $\begin{array}{lllll}\text { Brazilian Society of Electromagnetism-SBMag } & \text { C 2019 SBMO/SBMag (cc) BY } & \end{array}$ 


$$
i_{r d_{r e f}}=-\frac{2 Q_{r e f} L_{s}}{3 v_{s} L_{M}}+\frac{\lambda_{s}}{L_{M}}
$$

Then, the PWM algorithm calculates the switching signals to be applied on rotor side converter by means the rotor voltage vector in $\alpha \beta r$ reference frame.

\section{B. Considerations about the machine saturation in the control design}

To guarantee that the DFIG operates non-saturated condition the design of the controller must consider some aspects as the limitation of the voltage applied to the rotor and the absence of the overshoot. In this way, the mentioned items can reached by adding a limiter on computed rotor voltage output or by choosing no overshoot $(M P=0)$ and damping ratio $\xi \leq 1$ in this proposed state feedback controller applied to rotor current control. So, it means that the machine does not operate above the nominal values of voltage. To guarantee the cited operation condition the core of DFIG will be analyzed by finite element method simulation.

\section{FINITE ELEMENT SIMULATION}

The main objective of finite element method simulation is to predict under a specific value of slip the flux density level in the induction generator ferromagnetic material. Based on the stator and rotor flux density levels, it is possible to check some potential saturation that can to prejudice the operation of control system behavior. Since the machine is operating in a DFIG arrangement, the injection of currents in the rotor is required through a power converter in order to maintain the correct frequency and power to the grid.

Thus, a simulation was done with a current of 2.23 A injected into to the slip rings (Fig. 3). Furthermore, a rotor current frequency of $6 \mathrm{~Hz}$ was adopted according to the condition of the slip. These values of current and frequency were obtained during the laboratory tests in the prototype. The tables III, V and VI show the data of the prototype.

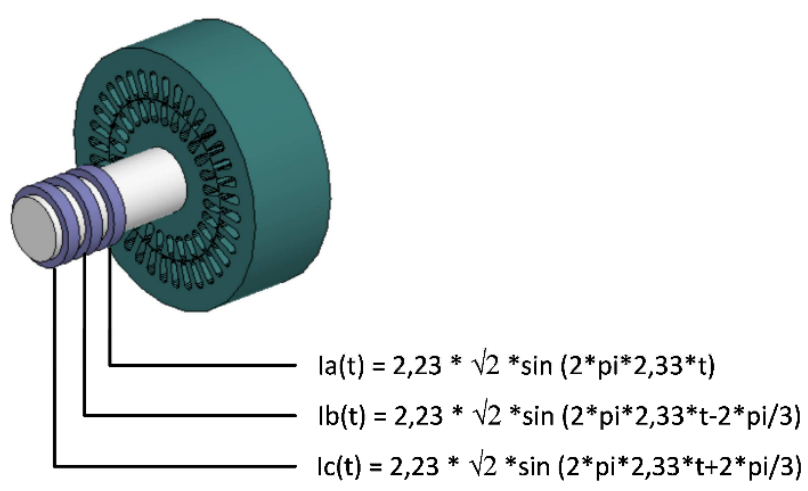

Fig. 3. Slip rings of DFIG.

\section{A. Magnetic Transient Simulation}

The purpose of the magnetic transient regime simulation is to evaluate the flux density levels in the ferromagnetic material of the generator. The problem formulation with constant speed, according to the equation $(30)$, is $[17,18]$ 


$$
\nabla \times v \nabla \times \vec{A} p=\vec{J} a-\sigma_{x} \frac{\partial A p}{\partial t}-\sigma_{x} \nabla \mathrm{V}+\nabla \times \vec{H} c+\sigma_{x} \omega \times \nabla \times \vec{A} p
$$

Were the constants $v$ the magnetic reluctivity, $\sigma_{x}$ electric conductivity and $\omega$ the speed in steady state, $\mathrm{V}$ is the scalar electric potential of the source, $\mathrm{Hc}$ is the permanent magnet coercive force, which is zero in this case, due to the fact that there are not permanent magnets, the vector $J a$ is the current density of the conductors and Apis the vector potential. The table I shows the quantities used in this simulation.

\begin{tabular}{lc}
\multicolumn{2}{c}{ TABle I. Simulation DatA } \\
\hline Scalar Electric Potential (V) & $220 \mathrm{~V}$ \\
Operation speed (n) & $1730 \mathrm{rpm}$ \\
Grid frequency & $60 \mathrm{~Hz}$ \\
Rotor frequency $(\mathrm{s}=60.0,03884)$ & $2,33 \mathrm{~Hz}$ \\
Simulation time & $0,01 \mathrm{~s}$ \\
Time step & $0,0001 \mathrm{~s}$ \\
\hline
\end{tabular}

The memory size of the computer is limited as well as the symmetry of the problem, is much more convenient to use a half of the geometry. The Fig. 4 represents the detailed geometry used and Fig. 5 the boundary conditions of the vector $A p$.

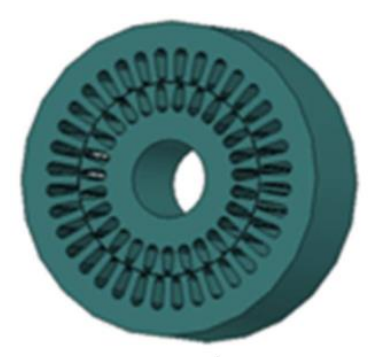

a)

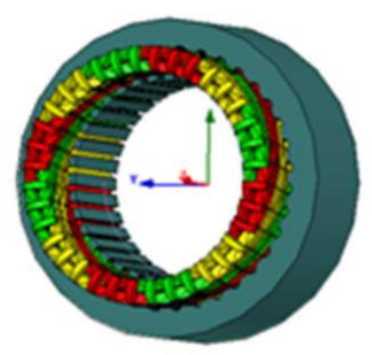

b)

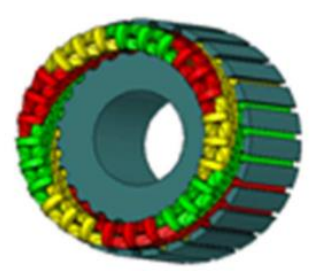

c)

Fig. 4. Detail of the geometry. a) Stator and rotor. b) Winding stator. c) Winding rotor.

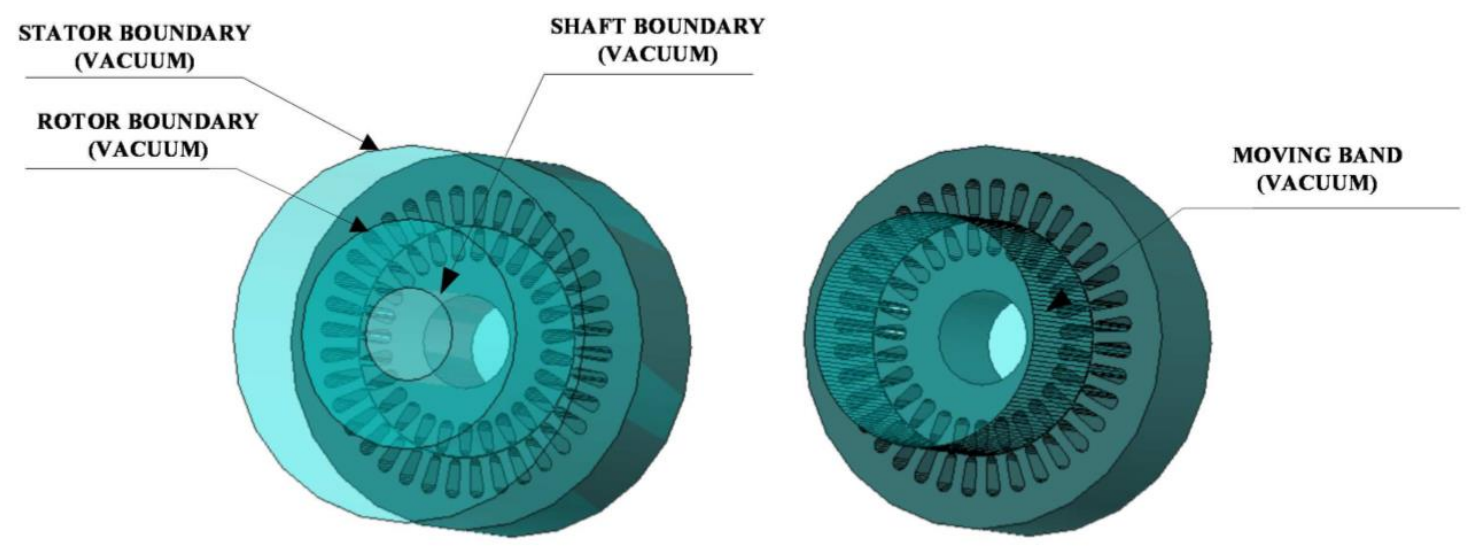

Fig. 5. Specific boundaries, physical properties and moving band for magnetic transient analysis.

The ferromagnetic material used during the simulation step was the 1010 carbon steel in which $\mathrm{BH}$ magnetization curve is presented in the Fig. 6 . 
Journal of Microwaves, Optoelectronics and Electromagnetic Applications, Vol. 18, No. 3, September 2019351 DOI: http://dx.doi.org/10.1590/2179-10742019v18i31497

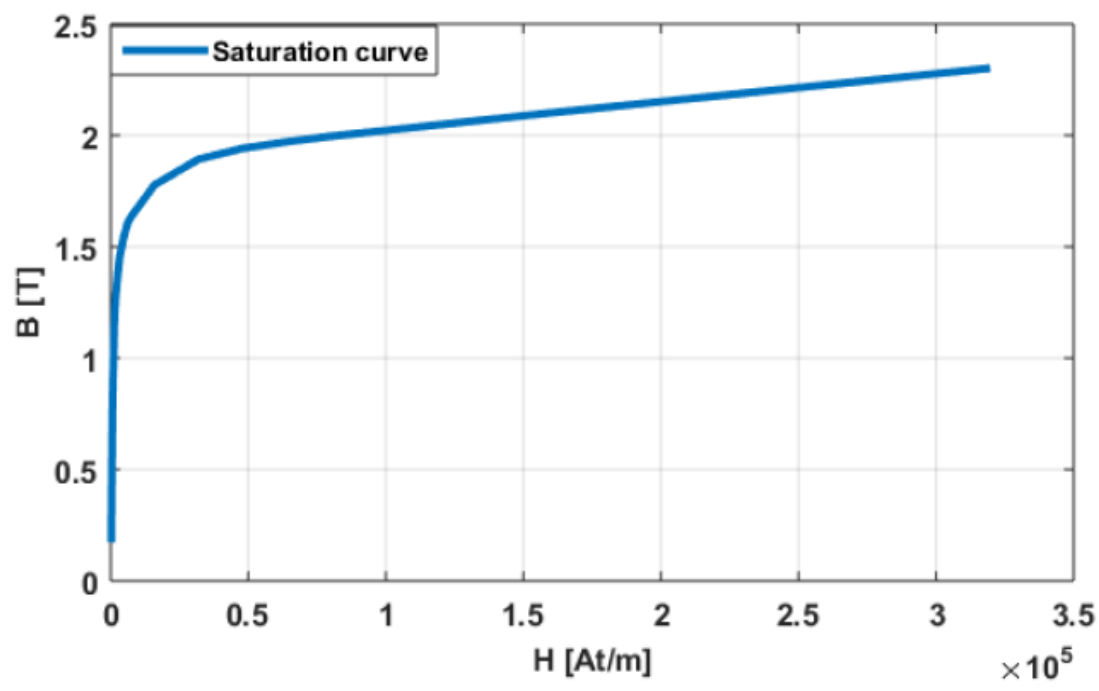

Fig. 6. BH curve of the 1010 carbon steel used in the stator and in the rotor.

The Fig. 7 represents the results obtained from the computational simulation. The color map shows the levels of flux density in the stator and in the rotor of the induction generator according to the conditions described previously.
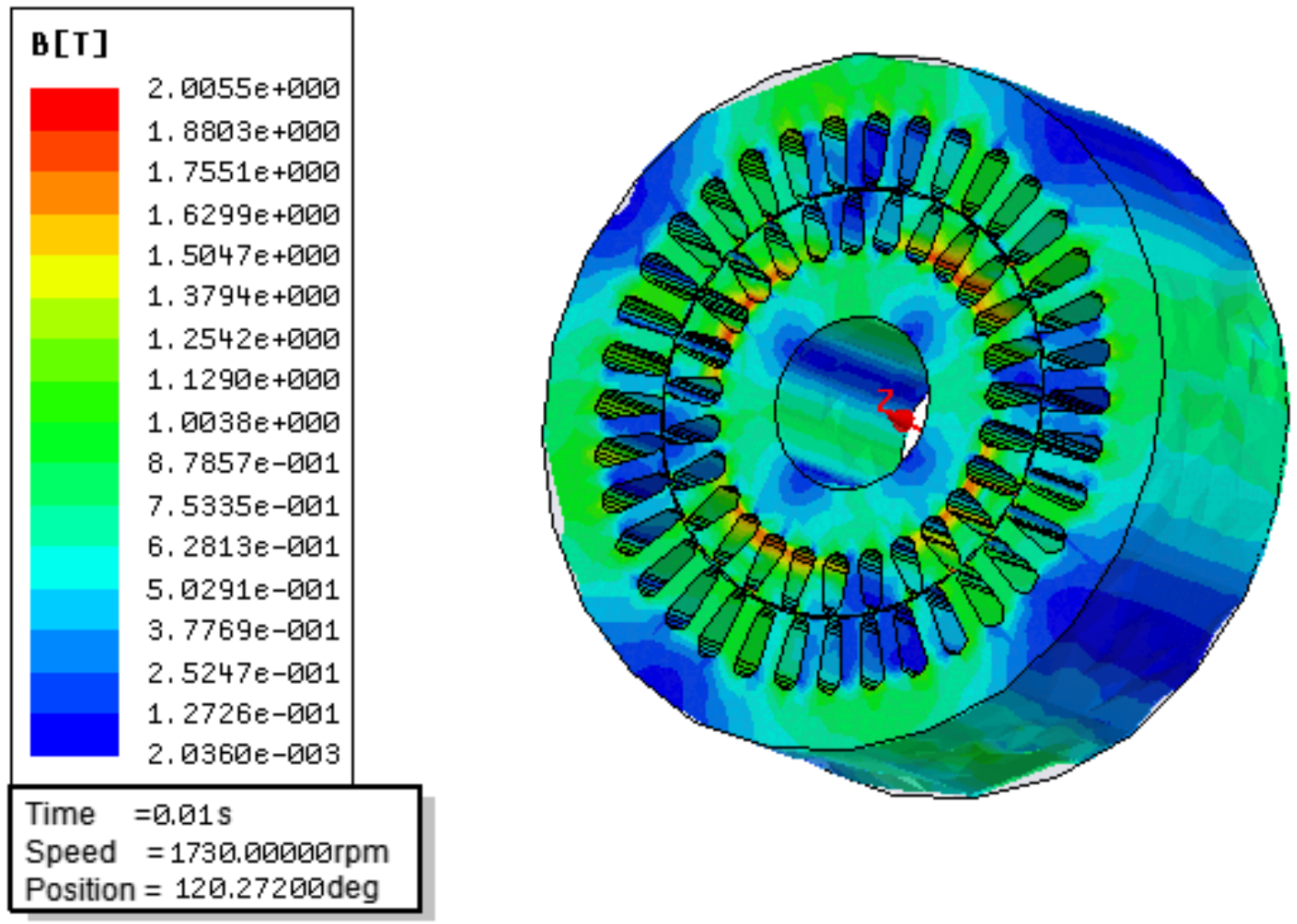

Fig. 7. Flux density color map for arms current of $2.23 \mathrm{~A}$ in the rotor.

\section{EXPERIMENTAL RESULTS}

To validate the proposed control system, the state feedback controller was first verified under Simulink ${ }^{\circledR}$ environment using our local machine parameters whose nominal values are given in 
Table III as well as the control loop parameters in Table IV calculated as on power control subsection.

The experimental setup is shown in Fig. 8. A variable speed DC motor coupled to the DFIG axis was used to transmit a torque equivalent to that generated by the blades of a wind turbine. The power control is performed by a DSP model TMS320F28335 which receives the instant readings of current and voltage hall sensors along with the pulsed rotor speed measurement from a differential encoder of 3600 pulses per revolution. The voltage vectors to be applied to the rotor of the machine are subjected to space vector modulation with a sampling rate of $10 \mathrm{KHz}$. The control of the grid-side converter has not been implemented and therefore the DC link voltage is obtained by an uncontrolled rectifier, being kept close to $210 \mathrm{~V}$, a value slightly above the peak value of the phase voltage of the grid.

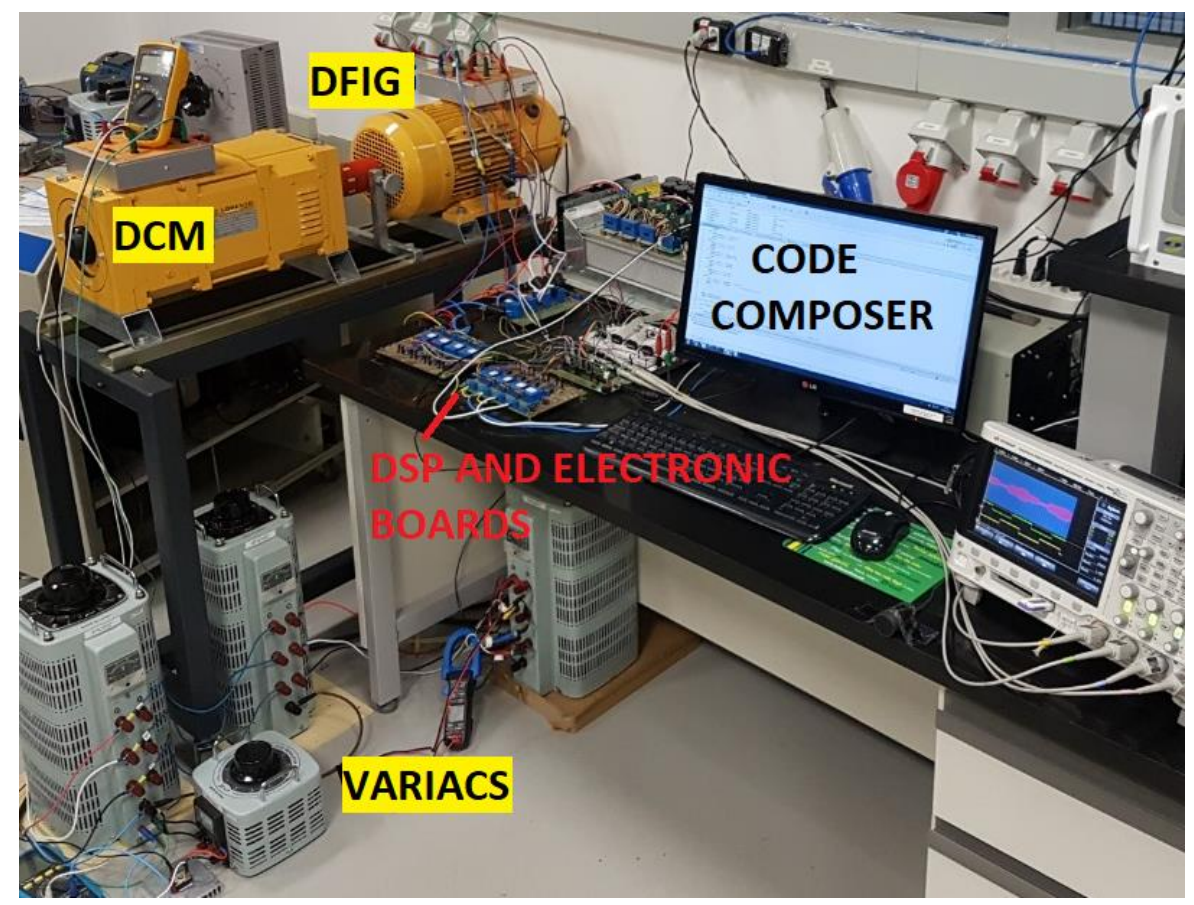

Fig. 8. DFIG test bench.

The following test was performed without torque control, ie, depending on the amount of power demanded, the machine axis can freely vary its rotation. With this, it is considered a constant machine speed, although the controller is able to exercise control also at variable speed, as discussed at the end of this section.

This first test is showed in Fig. 9 and composed of an alternating sequence of positive and negative steps in the direct and quadrature components of the rotor's current. Each half a second had its value modified, in which $I_{d r}$ and $I_{q r}$ were varied from 1 to $3 \mathrm{~A}$, giving four combinations. The respective power and angles for each pair are shown in Table II. When $I_{d r}$ and $I_{q r}$ were varied from 1 to 3 A the Flux density color map $f$ in the rotor can be seen in Fig. 7. 
Journal of Microwaves, Optoelectronics and Electromagnetic Applications, Vol. 18, No. 3, September 2019353 DOI: http://dx.doi.org/10.1590/2179-10742019v18i31497

TABLE II. PARAMETERS

\begin{tabular}{crrrr}
\hline$I_{r d}[A]$ & 1 & 1 & 3 & 3 \\
$I_{r q}[A]$ & 1 & 3 & 3 & 1 \\
\hline$P[W]$ & -384.25 & -1152.74 & -1152.74 & -384.25 \\
$Q[$ var $]$ & 1542.01 & 1542.01 & 773.61 & 773.61 \\
$f_{p}$ & 0.24 & 0.60 & 0.83 & 0.44 \\
$I_{A}[A]$ & 3.41 & 4.13 & 2.97 & 1.85 \\
\hline
\end{tabular}

Fig. 10 zoomed the moment when the $I_{d r}$ changes its value, in which we can observe a response time close to $2 \mathrm{~ms}$. Therefore, a positive angular mismatch can be observed in Fig. 11 at the crest of the current wave in relation to the voltage wave, when $I_{d r}$ decreases its value. In this case, there was a change in the power factor of the generator.

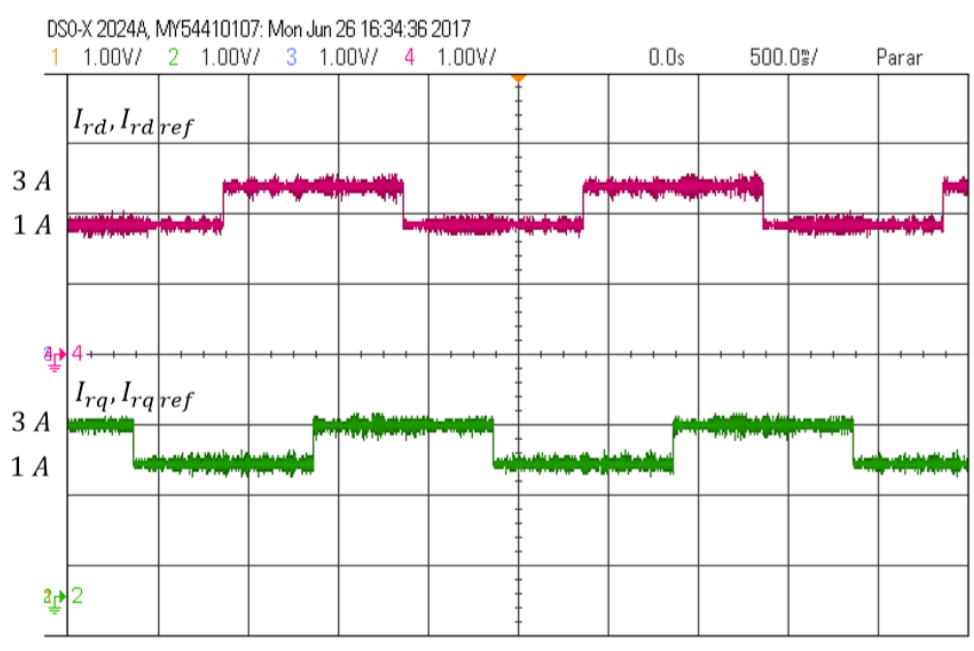

Fig. 9. Current test profile.

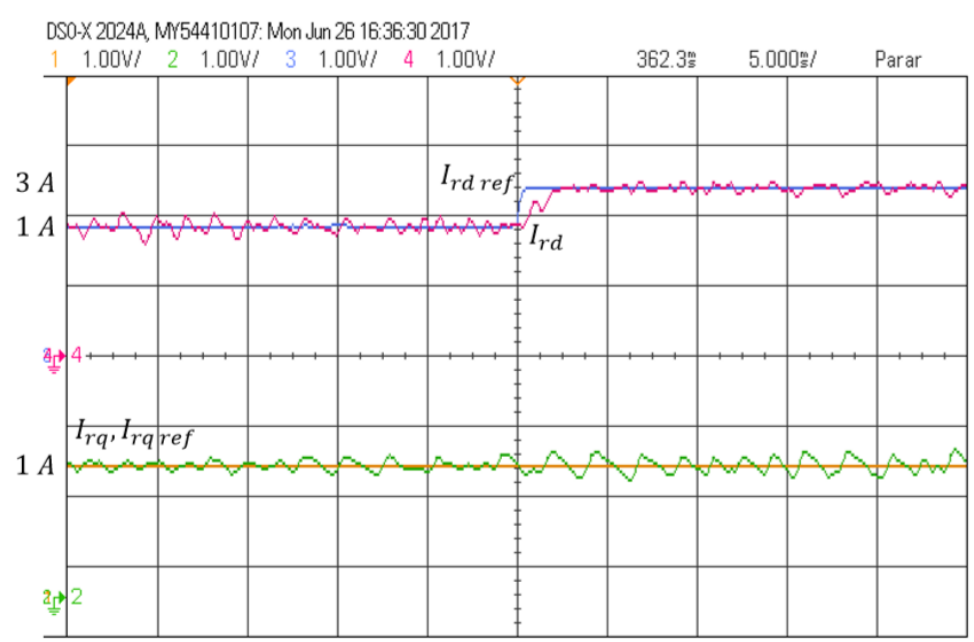

Fig. 10. Zoomed $\boldsymbol{I}_{\boldsymbol{r d}}$ transition.

Complementary, in Fig. 13 there is a remarkable increased amplitude in the current waveform since $I_{q r}$ is expected to control the active power delivered to the grid. By means of the Fig. 12 it is possible to measure that the response time of the controller is approximately $2 \mathrm{~ms}$, without any transient overcurrent during these instants, as expected by imposing critical damping on the plant and equal gains to both Brazilian Microwave and Optoelectronics Society-SBMO received 16 Oct 2018; for review 23 Oct 2018; accepted 11 July 2019 Brazilian Society of Electromagnetism-SBMag 
Journal of Microwaves, Optoelectronics and Electromagnetic Applications, Vol. 18, No. 3, September 2019354 DOI: http://dx.doi.org/10.1590/2179-10742019v18i31497

state feedback controllers.

In the second test shown in Fig. 14 the active and reactive power references are maintained at $1 \mathrm{~A}$ while the machine axis undergoes a speed variation from $1650 \mathrm{rpm}$ to $2100 \mathrm{rpm}$. The machine passes from the sub-synchronous operation in which it absorbs the power of the grid to feed the rotor, for the super-synchronous operation, to supply power by the rotor, together with the stator. This change can be observed at the figure center where a $180^{\circ}$ phase shift of the current wave $i_{r \alpha}$ occurs and its value remains constant at 1.4 A. The power of this test can be seen in Table II.

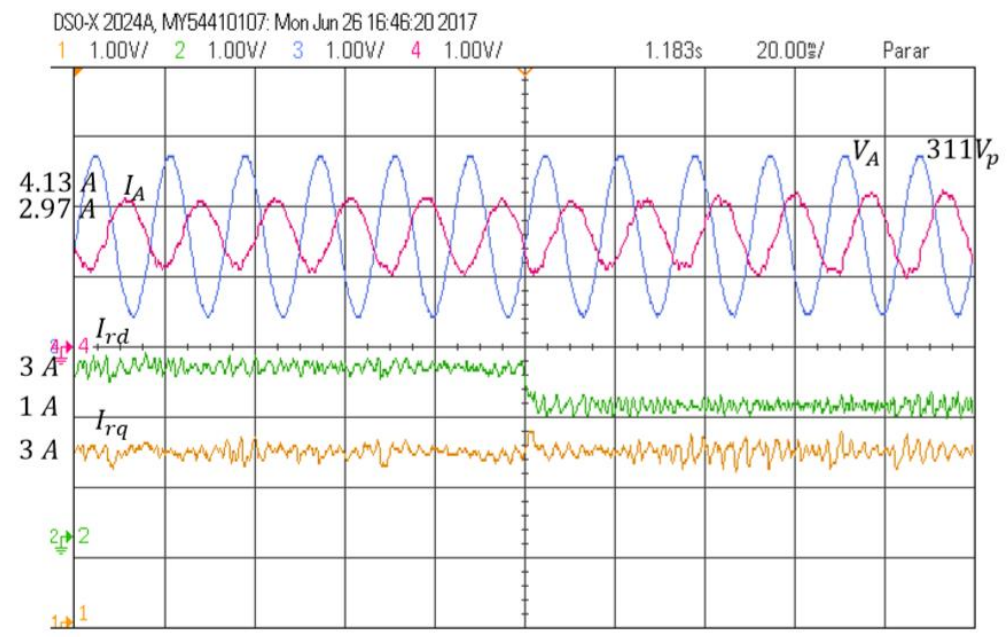

Fig. 11. Reactive power change: Step in rotor current $\boldsymbol{I}_{\boldsymbol{d}}$ while $\boldsymbol{I}_{\boldsymbol{q}}$ is held constant results on phase A stator current angle delay.

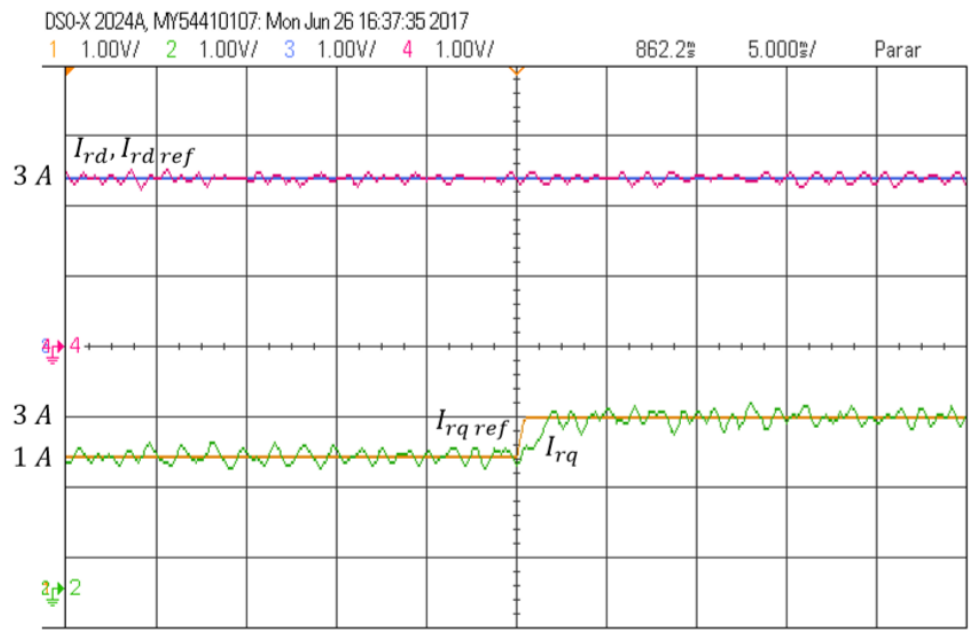

Fig. 12. Zoomed $\boldsymbol{I}_{\boldsymbol{r q}}$ transition. 


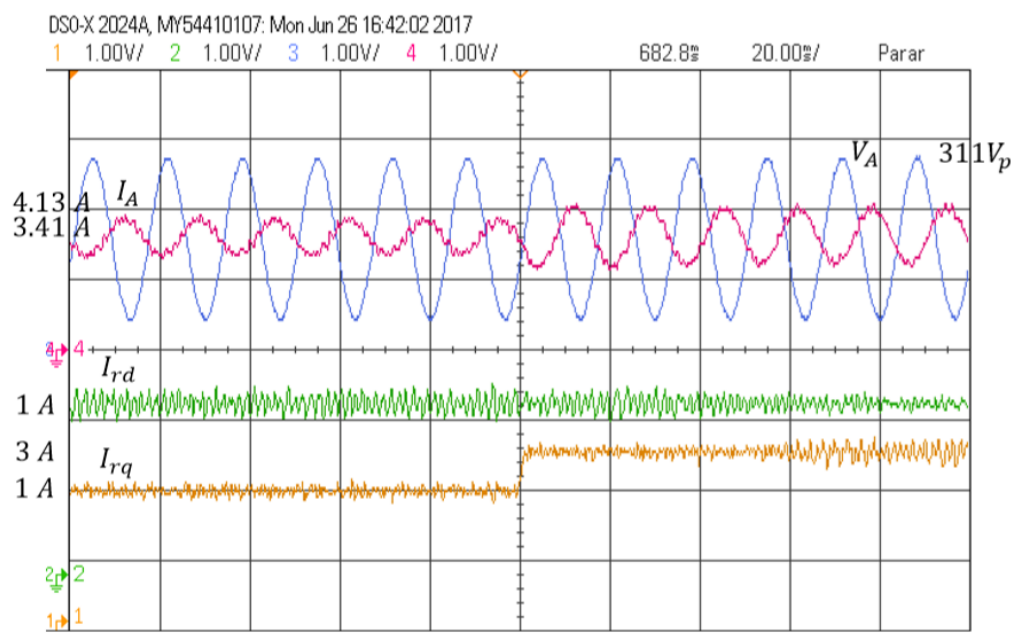

Fig. 13. Active power change: Step in rotor current $\boldsymbol{I}_{\boldsymbol{q}}$ while $\boldsymbol{I}_{\boldsymbol{d}}$ is held constant results on phase A stator current magnitude increase.

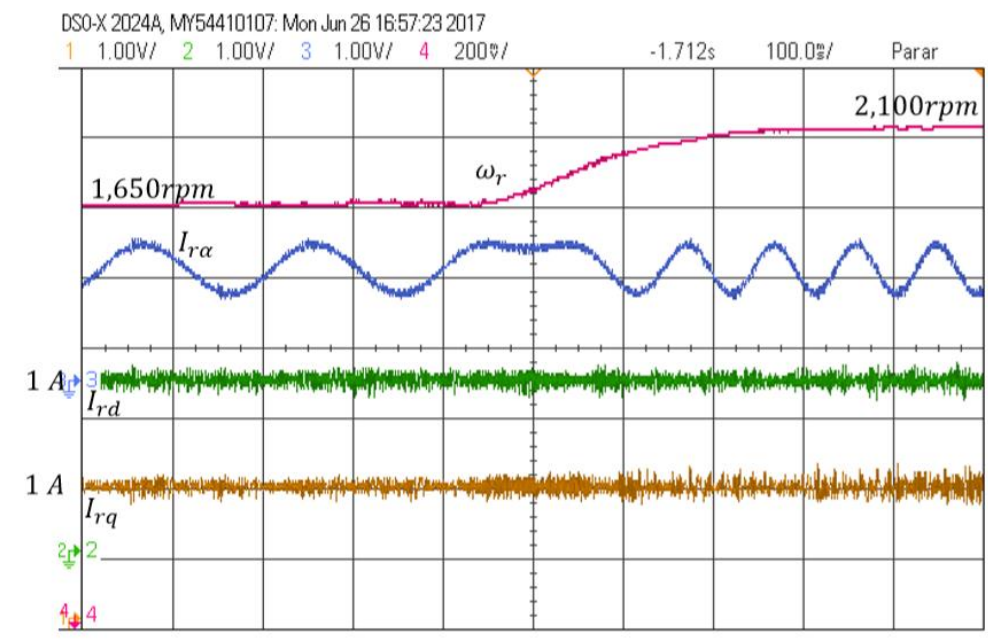

Fig. 14. Several wind speed operation.

\section{CONCLUSION}

The literature presents several strategies that can be used to control the power delivered to the network through DFIG, all of them searching for the compromise of the shortest response time $t_{s}$ with the lowest overshoot. Among them, from the most basic PI -when properly designed- it can bring satisfactory results.

Thus, in this paper the proposed state feedback power control allows to control the active and reactive power and it has about $2 \mathrm{~ms}$ of settling time. This shorter response time is due to the greater control effort of the controller, which use is justified and tested through finite element analysis, even if it indicates that the magnetic field in the core is close to its limit. The current overshoot, as less it seems could be further reduced if inductive filters were used in the mains connection. The results obtained at low power prototype show the performance of the controller in several operation conditions and they in accordance with the proposal.

Based on finite element simulation, in all parts of the DFIG geometry, the flux densities obtained Brazilian Microwave and Optoelectronics Society-SBMO received 16 Oct 2018; for review 23 Oct 2018; accepted 11 July 2019 Brazilian Society of Electromagnetism-SBMag 
Journal of Microwaves, Optoelectronics and Electromagnetic Applications, Vol. 18, No. 3, September 2019356 DOI: http://dx.doi.org/10.1590/2179-10742019v18i31497

were under the saturation point of the ferromagnetic material used which is about of $2.1 \mathrm{~T}$, consequently, the control system can operate in a correct way avoiding perturbation during the operation and it can be used for DFIG power control. In this way, the proposal avoids saturation points during the tests in which the losses can not increase and the mathematical model employed can be applied to the control design.

Hence, the state feedback power control with finite element analyses can be useful for DFIG power control.

\section{APPENDIX}

TABLE III. RATED MACHINE PARAMETERS

\begin{tabular}{lcl}
\hline \multicolumn{1}{c}{ Parameter } & Symbol & Value \\
\hline Total Power & $\mathrm{S}$ & $3 \mathrm{KVA}$ \\
Inertial constant & $\mathrm{J}$ & $0.05 \mathrm{Kg} . \mathrm{m}^{2}$ \\
Pole pairs & $\mathrm{PP}$ & 2 \\
Stator: [per phase] & & \\
Voltage & $V_{S}$ & $220 \mathrm{~V}$ \\
Current & $I_{S}$ & $11.45 \mathrm{~A}$ \\
Resistance & $R_{S}$ & $1 \Omega$ \\
Inductance & $L_{S}$ & $201 \mathrm{mH}$ \\
Rotor: [per line] & & \\
Voltage & $V_{r}$ & $440 \mathrm{~V}$ \\
Current & $I_{r}$ & $4.5 \mathrm{~A}$ \\
Resistance & $R_{r}$ & $3.13 \Omega$ \\
Inductance & $L_{r}$ & $201 \mathrm{mH}$ \\
Rated speed & $\omega_{m e c}$ & $1700 \mathrm{rpm}$ \\
Mutual inductance & $L_{m}$ & $191.7 \mathrm{mH}$ \\
\hline
\end{tabular}

TABLE IV. CONTROLLER PARAMETERS

\begin{tabular}{cl}
\hline Symbol & Value \\
\hline$\xi$ & 1 \\
$t_{s}$ & $2 \mathrm{~ms}$ \\
pol $_{1,2}$ & -645.1613 \\
$k_{1}, k_{2}$ & 6.6883 \\
$k_{i 1}, k_{i 2}$ & 1290 \\
\hline
\end{tabular}

TABLE V. STATOR DATA

\begin{tabular}{ll}
\hline Number of slots & 36 \\
Winding & Double layer \\
Coil pitch & 12 (slots) \\
Rated stator voltage & $220 \mathrm{~V}$ \\
Rated rotor voltage & $380 \mathrm{~V}$ \\
Rated stator current & $11.5 \mathrm{~A}$ \\
\hline
\end{tabular}


Journal of Microwaves, Optoelectronics and Electromagnetic Applications, Vol. 18, No. 3, September 2019357 DOI: http://dx.doi.org/10.1590/2179-10742019v18i31497

TABLE VI. ROTOR DATA

\begin{tabular}{ll}
\hline Symbol & Value \\
\hline Type & Slip rings \\
Number of slots & 27 \\
Winding & Double layer \\
Coil pitch & 7 (slots) \\
\hline
\end{tabular}

\section{REFERENCES}

[1] G. Abad, J. López, M. A. Rodríguez, L. Marroyo, and G. Iwanski, Doubly Fed Induction Machine: Modeling and Control for Wind Energy Generation Application. Wiley-IEEE Press, 2011.

[2] R. Zhu and Z. Chen, "Closure to discussion on "virtual damping flux-based lvrt control for dfig-based wind turbine," IEEE Transactions on Energy Conversion, vol. 31, no. 1, pp. 408-409, March 2016.

[3] B. Hopfensperger, D. J. Atkinson, and R. A. Lakin, "Stator-flux-oriented control of a doubly-fed induction machine with and without position encoder," IEEE Proc.-Electr. Power Applications, vol. 47, no. 4, pp. 241-250, April 2000.

[4] B. H. Chowdhury and S. Chellapilla, "Double-fed induction generation control for variable speed wind power generation,” Electric Power System Research, vol. 76, pp. 786-800, June 2006.

[5] A. Tapia, G. Tapia, J. X. Ostolaza, and J. R. Saenz, "Modeling and control of a wind turbine driven doubly fed induction generator," IEEE Transactions on Energy Conversion, vol. 18, no. 2, pp. 194-204, June 2003.

[6] F. Poitiers, T. Bouaouiche and M. Machmoum, "Advanced control of a doubly-fed induction generator for wind energy conversion,” Electric Power Systems Research, vol. 79, no. 7, pp.1085-1096, July 2009.

[7] A. L. L. F. Murari, J. A. T. Altuna, R. V. Jacomini, C. M. R. Osorio, J. S. S. Chaves, and A. J. Sguarezi Filho, “A proposal of project of pi controller gains used on the control of doubly-fed induction generators," IEEE Latin America Transactions, vol. 15, no. 2, pp. 173-180, Feb 2017.

[8] M. Mohseni, S. M. Islam, and M. A. S. Masoum, "Enhanced hysteresis-based current regulators in vector control of DFIG wind turbines," IEEE Transactions on Power Electronics, vol. 26, no. 1, pp. 223-234, Jan 2011.

[9] Z. Xin-Fang, X. Da-Ping, and L. Yi-Bing, "Predictive functional control of a doubly fed induction generator for variable speed wind turbines," In IEEE World Congress on Intelligent Control and Automation, vol. 4, pp. 3315-3319, June 2004.

[10] J. Morren and S. W. H. de Haan, "Ride through of wind turbines with doubly-fed induction generator during a voltage dip," IEEE Transactions on Energy Conversion, vol. 20, no. 2, pp. 435-441, June 2005.

[11] X. C. Guo, and Y. Gong, "Decoupled control of active and reactive power for a grid-connected doubly-fed induction generator," In Third International Conference on Electric Utility Deregulation and Restructuring and Power Technologies DRPT 2008, pp 2620-2625, April 2008.

[12] S. Mishra, Y. Mishra, Fangxing Li, and Z.Y. Dong, "Ts-fuzzy controlled dfig based wind energy conversion systems," IEEE Power Energy Society General Meeting PES ’09, pp. 1-7, July 2009.

[13] E. Kamal, M. Oueidat, A. Aitouche, and R. Ghorbani, "Robust scheduler fuzzy controller of DFIG wind energy systems," IEEE Transactions on Sustainable Energy, vol. 4, no. 3, pp. 706-715, July 2013.

[14] A. J. Sguarezi Filho and E. Ruppert Filho, "Model-based predictive control applied to the doubly-fed induction generator direct power control," IEEE Transactions on Sustainable Energy, vol. 3, no. 3, pp. 398-406, July 2012.

[15] R. V. Jacomini, F. S. Trindade, A. J. Sguarezi Filho, and E. Ruppert Filho, "Decoupled power control for doubly-fed induction generator using sliding-mode control," Przeglad Elektrotechniczny, vol. 8, no. 89, pp. 100-105, August 2013.

[16] A. Susperregui, M. I. Martinez, I. Zubia, and G. Tapia, "Design and tuning of fixed switching-frequency second-order sliding-mode controller for doubly fed induction generator power control," IET Electric Power Applications, vol. 6, no. 9, pp. 696-706, December 2012.

[17] T. D. Strous, X. Wang, H. Polinder, and J. A. Ferreira, "Saturation in brushless doubly-fed induction machines," In 8th IET International Conference on Power Electronics, Machines and Drives (PEMD 2016), pp. 1-7, April 2016.

[18] X. Wang, T. D. Strous, D. Lahaye, H. Polinder, and J. A. Ferreira, "Finite element modeling of brushless doubly-fed induction machine based on magneto-static simulation," In 2015 IEEE International Electric Machines Drives Conference (IEMDC), pp. 315-321, May 2015.

[19] W. Leonhard, Control of Electrical Drives. Springer-Verlag Berlin Heidelberg New York Tokyo, 1985.

[20] J. Holtz, J. Quan, J. Pontt, J. Rodríguez, P. Newman, and H. Miranda, "Design of fast and robust current regulators for high-power drives based on complex state variables," IEEE Transactions Industrial Applications, vol. 40, no. 5, pp. 13881397, September/October 2004.

[21] A. J. Sguarezi Filho and E. Ruppert Filho, "The complex controller for three-phase induction motor direct torque control," SBA Controle e Automação, vol. 20, no.2, pp. 256-262, 2009.

[22] K. Ogata, Engenharia de Controle Moderno. LTC, 2000.

[23] R. C. Dorf and R. H. Bishop, Modern Control Systems Analysis \& Design. Addison Wesley, 1998. 